\title{
Handling Mouldings in Historic Architecture: a Matter of Geometry, a Matter of Knowledge?
}

\author{
Jean-Yves Blaise ${ }^{1}$, Iwona Dudek ${ }^{1}$, Livio De Luca ${ }^{1}$ \\ ${ }^{1}$ UMR CNRS/MCC 694 MAP, EAML, 13288 Marseille cedex 09, France (jyb, idu, ldl@map.archi.fr)
}

\begin{abstract}
The design and the making of mouldings in historic architecture is a good example of how complex relations of geometric features to semantic ones can be. Can architects who deal with historic artefacts, and who practice with computer solutions from the engineering world, still handle knowledge before handling geometry? This paper presents two very different case studies through which comprehensive analysis/ modelling /representation processes have been implemented. In a converging conclusion, it introduces a visual codification of mouldings. The contribution underlines the benefits of implementing a robust theoretical model of mouldings in the analysis of historic artefacts, notably in order to facilitate comparative dating, survey operations, typology analysis.
\end{abstract}

Keywords: Modelling, Classification, Visualisation

\section{INTRODUCTION}

An amateur's observation of a number of historic artefacts would be enough to understand how important mouldings have been in the design of edifices throughout history. And this observation can be confirmed by writings that would cover several shelves of a library (starting with Vitruvius or Palladio [2], continuing with [1], [3], [4], [5], [6], [7], etc.). The impact and importance of the notion of moulding has, in the theory of architecture, been clearly assessed: mouldings are described as a tool in the composition of shapes, but also one of the means through which shapes and consequently the artefact itself are given a meaning.

Can architects who deal with historic artefacts, and who practice with computer solutions from the engineering world, still handle this notion? Do nurbs and splines fruitfully replace ovolos, ogees, beaks and cavettos, or do they overemphasise geometric features above semantics? Can something be done to integrate the semantics of architecture with the constraints of geometry? At the end of the day, the issue here is simple: is there more to a moulding than its shape? The answer is naturally yes, intuitively. But what makes the difference?

In this paper we point out possible answers, by cross-examining two experiences that widely differ from one another in terms of corpus and of objectives. Through both these experiences we implemented and evaluated a thorough analysis - conceptual modelling implementation - exploitation process. The contribution underlines the benefits of implementing a robust theoretical model of mouldings in the analysis of historic artefacts, notably in order to facilitate comparative dating, survey operations, typology analysis. Shortly said, our position is that mouldings become a matter of geometry once they have been understood as a matter of knowledge.
The paper starts with a short introduction to the vocabulary of mouldings that we will use, and a definition of the research issue, before briefly presenting the two above mentioned experiences and finally concluding on convergence and outcomes.

\section{A VOCABULARY OF MOULDINGS}

Literature shows that the word moulding has a rather consensual definition, more or less in accordance with this of [6]: "Any of various long, narrow, ornamental surfaces with uniform cross sections and a profile shaped to produce modulations of light, shade and shadow». Basing complementarily on 2D and 3D aspects underlined by the above-mentioned definition we, in this paper, will introduce four different notions. It appears necessary in order to facilitate the reading of this contribution to define these notions though an adequate vocabulary:

- Primary curves (curves using only one set of parameters)

- Canonical curves - i.e. a moulding (composed of one or several 2D primary curves, and corresponding to a canonical, meaningful architectural figure like cymas or reedings).

- Profiles (outline of a 2D arrangement of canonical curves that can be extruded or rotated to produce volumes, such as an architrave).

- Groups of mouldings (3D arrangements of volumes that can combine rotated and extruded profiles).

\section{THE ISSUE}

If we are to understand and explain where and how geometry intervened in the making of mouldings in historic architecture, we need to understand and represent the way they mouldings were thought, 
designed. Observing by the sole means of geometry a group of mouldings - i.e. the result- is not enough. We need to understand the elements a group of mouldings is made of - i.e. the means. And these means intersect the language of geometry and the language of architecture. In other words, if we are to understand the artefact's ornament, we need to define shapes that can be described by geometric features (profiles, extrusion vector, etc.) but that are designed as answers to architectural constraints (light, shadow, but also symmetry, material, culture, etc.). This ambiguity calls for an investigation aimed at better defining relations between an architectural object, and its geometrical definition. A number of issues are raised:

- What is the role of geometry in the differentiation of architectural concepts?

- How are geometric features represented by architects?

- How can geometric / architectural features of objects (here profiles, canonical curves, groups of mouldings) be best compared?

As will be seen, the notion of moulding questions in an accurate and exemplary manner the relations of an artefact's geometrical features to its architectural features, and we expect the two experiments introduced hereafter to provide at useful hints about these relations.

\section{A FIRST ANALYSIS GRID: THE WOODEN CEILINGS CASE}

In his brilliant analysis of the corpus of elements used in the construction of wooden ceilings in Poland, J.Tajchman [8] introduces several classifications:

- A classification of canonical objects (beams, joists, decking, etc.).

- A classification of how objects are assembled modes (one to another, or with walls).

- A classification of profiles.

- A classification of endings of groups of mouldings.

- A classification of arrangements of ceilings.

Each classification corresponds to a given point of view on the components of a wooden ceiling. His analysis is the result of a comprehensive inventory work from which the author derives rules that can be used to describe autonomously various aspects and propose systematic classifications based on an extension mechanism. An analysis covers construction techniques as well as decorative aspects and relates them to different periods of history, and different areas of influences. J.Tajchman clearly establishes a dependency relation of a profile, its ending, its assembling mode, to a specific time slot, and a specific geographical area. Accordingly, his classifications result can allow conservators to date ceilings or to identify in a ceiling elements reused from another, or ill-combined.

What his methodological proposition tells us first is that, even when dealing with a very narrow corpus of elements, there is more to an architectural object than its geometric features. If we are to understand the whole object, including its relations with other elements in time and in space, we need to handle and combine several semantic layers - some dimensional, some morphological, and some historical. We have developed, and introduce here briefly, a theoretical model that reinterprets his classification effort, with a particular focus put on the generic description of mouldings of beams. The issue is simple: how can we combine in a unique, workable, theoretical (but computer-implemented) model various points of view? Furthermore, can we foster re-uses and comparisons by better defining relations of a morphology to its basic geometric components? In the following sections we give a quick overview of an implementation based on OOP paradigms as summarised in [10], and underline some of this experiment's outcomes and limits.

\subsection{Principles of the implementation}

In an early stage of this research we chose to identify objects (in the sense of Tajchman's classification of canonical objects, but also in the sense of OOP) within which various sets of properties would be in charge of handling points of view. The resulting implementation proposes two levels of characterisation:

- An architectural semantics level where objects correspond, roughly speaking, to the concepts architects use when they portray things they make or see: «a beam » and not « a poyhedron » for instance. What is the difference? Geometric complexity? Certainly not, some beams are polyhedrons or almost. There are many differences, but let us here quote only two: historic variability of a concept (a polyhedron does not vary with time, a beam does) and the notion of scale (coming closer to a polyhedron does not change one's perception of it -unless fog is particularly thick - whereas coming closer to a beam does - nature of the material used, cracking, remaining pigments, micro-readings of decorative details, etc.). So at this semantic level objects reification is obtained through the identification of univocal form+function pairs, as described in [11], and not through specific morphological features. For instance, a post may resemble a joist, but their functions differ both concepts should exist. This approach goes beyond the wooden ceilings case, and has been applied to other corpuses of elements (see [11]). Concepts are implemented as classes in the senses of OOP; with two complementary factorising mechanisms: addition of properties for regular classes, functional categorisation for abstract classes.

- A geometric services level, where objects are in charge of describing significant morphological variations of objects of the higher level. In other word, as mentioned in [12] this level is in charge of handling the morphological tolerance of a concept: whether a beam has rich or poor mouldings, whether it has any or not, it remains a beam. To be true, objects at this level include more than 
geometric properties (dating, material, etc.). But let us say here clearly that we wish to focus now on only those descriptors useful in describing the morphology of higher level objects. These descriptors include dimensional indicators, but also more complex geometric entities like beam endings. Classes built here act in a part-of relation with higher level objects.

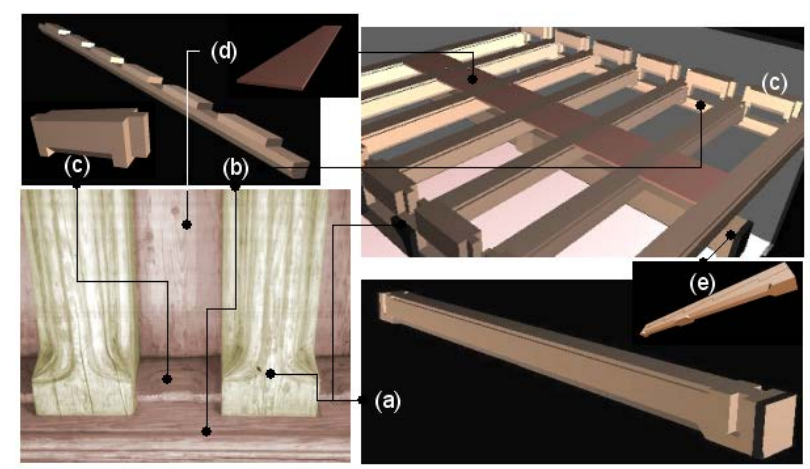

Fig 1: Isolating univocal form+function pairs on the corpus of wooden ceilings: (a) joists (b) rim joist (c) bridging (d) decking (e) beam.

\subsection{A generic mechanism to describe the geometry of mouldings.}

Once the necessity of having a geometric services level established, we remained with the task of developing a solution that would allow the handling and the reuse of these services across experiments.

Analysing closely F.D.K Ching's definition of mouldings (see section $2-[6]$ ), an ambiguity appears over the relation of a profile to a moulding:

- A moulding is defined (in terms of geometry) by a profile and its generation.

- From a profile one can build various groups of mouldings.

Once again, as mentioned in [12], the flexibility of ethnic languages allows a term to embrace meanings that become inconsistent when the time has come to list, define and type attributes. In this experiment we have identified and implemented two independent concepts:

- $\quad$ The concept of moulding, corresponding to primary or canonical curves (ovolo, cavetto, etc.).

- The notion of profile, a more generic concept that combines one or several Mouldings (simple combination - like cymas or ogees; or complex ones - like bases).

Both are "2D concepts": once nested as part-of "3D concepts" at the semantic level - such as beams, joists, etc. - they contribute to the morphology of the object in manners that may differ (extrusion, rotation, both, etc.). Both Moulding and Profile are classes in the sense of OOP: we use hereafter italic and a capital letter when referring to the classes, their subclasses or instances. An instance of the Moulding class is defined by:

- two control points (startPoint, endPoint - xy plane)

- a "type" that identifies convexity/concavity and curve (quarter-circle, half-circle, scotia, etc.)

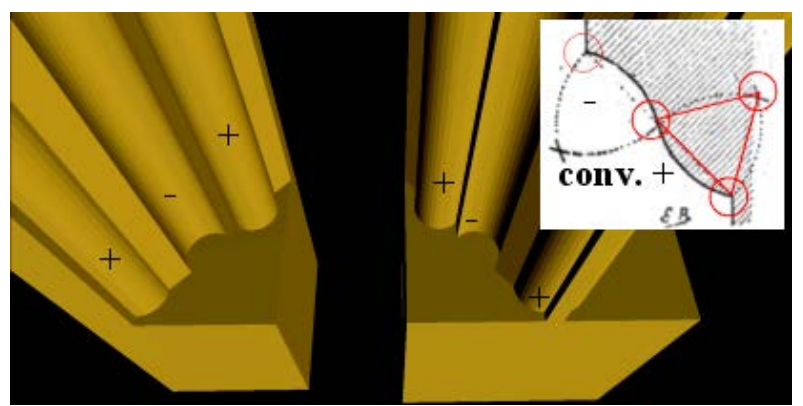

Fig 2: J. Tajchman's Plus / Minus notation used for quarter-circles (cavettos) on (left) a rim joist and (right) a joist. Top right, principle of the notation illustrated on a cyma (recta) drawn by [1]

a pointsContainer in charge of storing the intermediary points that will eventually be needed to draw the moulding in non-CSG modellers.

A method of the Moulding class is in charge of operations needed to allocate the pointsContainer using three parameters: control points, curve type and user-chosen level of detail (i.e. number of segments to display between control points).

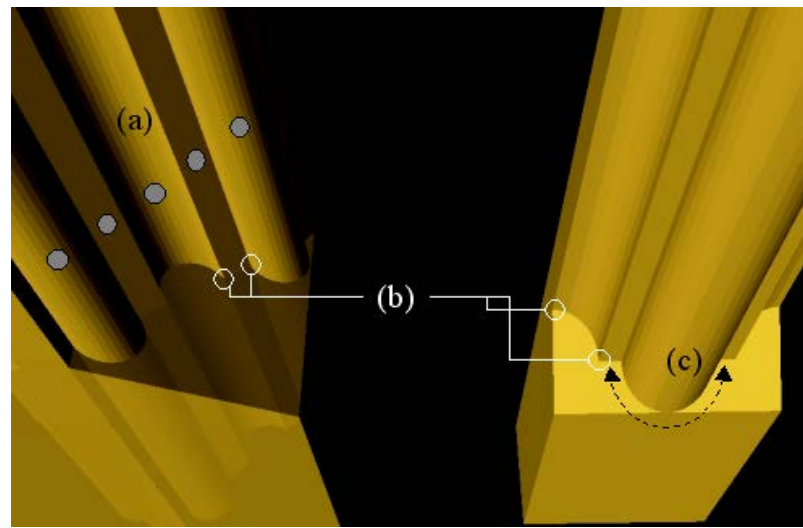

Fig 3: (a) Mouldings (b) control points of each moulding (c) intermediary points of a Semi-circle Moulding with parameter pointsContainer $48 \mathrm{seg} / 360^{\circ}$.

Accordingly, a difference is made between the theoretical definition of the object and its actual representation using this or that modelling platform. Instance of the Moulding class act as attributes of the Profile classes.

In the FlatProfile class (representing one or several fillets, bands, fascias, etc.) only the successive control points of each Moulding are needed to draw the profile. The MouldedProfile class refines the above mentioned, with here complex curves between control points. For each (control points, curve type) pair a method of MouldedProfile instances a Moulding which calculates its specific pointContainer. Semantic level objects can generate different 3D shapes, from the reading of Profiles, depending on the "semantic context": joists, archstones, window frames, etc. Accordingly, 3D shape 
generation can be linear (corbels, rim joists, etc.), linear and symetric (joists, etc.), multilinear - i.e. shapes with returns (window frames, architrave, etc.), and eventually use more complex curves (trefoils for instance).
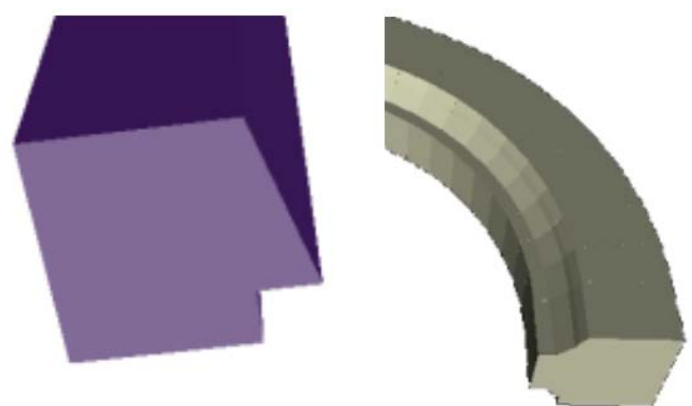

Fig. 5 -FlatProfiles on a window frame and an arch : knowing control points is enough to represent the object.

As a result, given only a list of control points and of curve types, the MouldedProfile object is capable of providing an exhaustive geometric representation.

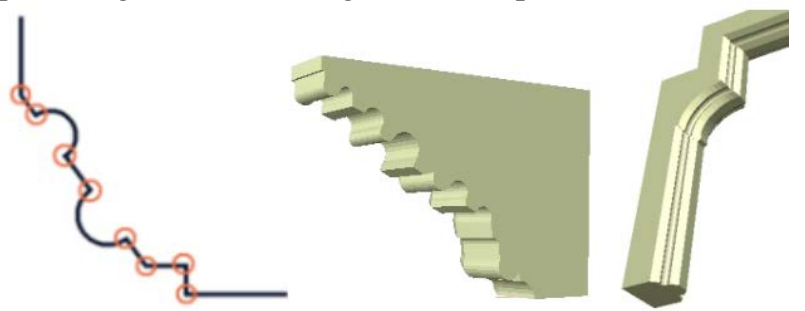

Fig 6: Left, principle of the succession of control points. Middle, linear generation of a corbel from a Profile on the case of corbels. Right, complex generation on the case of a doorway.

In other words, the semantic description of the profile replaces a thorough geometric definition: elements of knowledge are capitalised in order to facilitate and accelerate the geometric modelling step (an issue encompassing engineering-centred activities like surveying [13] and human sciences-centred analyses like history of architecture). Semantics are capitalised at two levels: the amount of information needed to instance objects at the semantic level is lowered, the amount of geometric information needed to instance Profiles is lowered.

The initial implementation (Perl/VRML/ $\mathrm{XML}$ (XHTML) is a rather primitive one, chosen for freeware visualisation compliance. It yet allows users to create and display visually instances of objects for which only control points and curve types are known. The type's specification is done using an Integer scale based on J.Tajchman's +/- convexity indicator [8].

\subsection{Outcomes and limits.}

This experiment has shown that, basing on the pragmatism of OOP techniques [9], an efficient compromise can be reached between a semantic level (matching the language of the architect) and the necessity of exhaustive geometric modelling. A number of remaining issues should here be quoted: only regular curves actually implemented, morphological tolerance addressed only at semantic level (see [12]), deformations and partial destruction ill-handled. Still, in short, the experiment does underline possible benefits of the approach in terms of cost, a hot topic notably in surveying and representation scientific communities where too often more is less. However our position is that beyond this benefit in terms of efficiency, this generic mechanism can be exploited not only in a traditional architectural representation perspective, but can also be exploited in an information visualisation perspective more suitable to comparisons and cross-examination of clues.

\section{THE SECOND EXPERIMENT: CLASSICAL ARCHITECTURE}

In this second part we focus on the elements of mouldings of the classical period. Basing on historical sources and on direct observation, [7] has proposed a classification of mouldings and shown in a systematic manner the role they play in the composition of edifices. He identifies mouldings as the smallest physical units atoms- of classical architectural (14 types identified), and investigates the way they are combined. He thereby provides a consistent theoretical background that we exploit in order to propose a generic formalism dedicated to the representation and the handling of mouldings in the context of a 3D modelling effort. The formalism proposed bases on a comparative analysis of mouldings of the classical period that allows us to provide a number of statements:

- A moulding results from the combination of linear or curvilinear segments.

- A geometric transition within a profile (or inside a moulding) is based on the perpendicularity of two constructive planes

- Complex curves within a moulding (convex or concave) result from the deformation of its envelope or of a polycentric construction of tangent arcs.

- A surface results from a generating profile and of a path.

- Profiles and paths are orthogonal (even when the latter is a curve)

- A path results from the combination of the same geometric entities as the mouldings themselves, but at a different scale.

The formalism presented identifies several description levels, with a semantic level acting as an integrator of nested geometric levels.

\section{A VISUAL CODIFICATION AS A BRIDGE}

At first glance, the two experiments we have presented mostly result in gains of efficiency at modelling time. However our position is that benefits of 
understanding and handling the cognitive nature of mouldings should go beyond and calls for a better integration of the traditional architectural representation perspective, and of the information visualisation perspective, as mentioned in [15].

Accordingly, we currently focus on the emergence and evaluation of a visual language underlining a convergent understanding of the semantics behind mouldings. The reader should however not see in this section any other claim than this one: because there is knowledge in mouldings, before geometry, it is possible to bridge technological gaps such as those illustrated by our two experiments.

In his analysis of wooden ceilings, J.Tajchman proposes a simple and efficient codification of mouldings (see figure below) based on the idea of counting convex/concave shapes. The codification's outcome is clear: groups of "comparable” objects (with regards to the codification) are first identified. By analysing the content of each group, regional or temporal "rules" can then be established or denied.

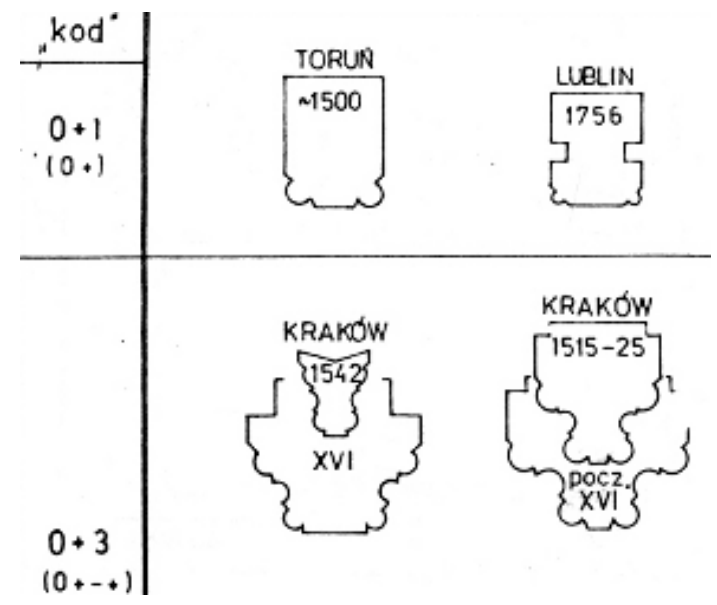

Fig 3: J.Tajchman’s codification of mouldings

But as shown on the figure above, his codification is restrictive and dedicated to the sole case of ceilings (only circular curves, no indication of proportion of curves to one another or to the whole profile, no flat mouldings, etc.). We propose a generic visual codification that summarises the following features:

- $\quad$ Type and orientation of curve

- Size of curve (distance between control points) relatively to the biggest one

- Concavity / convexity

- $\quad$ Percentage of the profile's moulded parts relatively to the whole profile

- Type of generation of the profile (linear, return, curvilinear)

- Compositional rules (symmetry in particular)

The visual disposal is linear, and exploits the following four graphic variables (as defined in [16]):

- $\quad$ Size (size of curve, Percentage of moulded parts)

- $\quad$ Shape (Concavity / convexity)

- Colour (type of curve)
- $\quad$ Value (Compositional rules)

- Orientation (orientation of curve)

A first evaluation of the visual disposal is currently being carried out at two levels:

- $\quad$ pairing tests (matching codes with profiles, and profiles with codes) for readability assessment.

- $\quad$ cross-examination tests (comparing codes to codes) to test the ability of the disposal to uncover the evidence in the sense of E.R Tufte [17].

Provided results of the evaluation are satisfactory, an implementation on the two experiments previously described, or on other case studies, will be needed so as to weigh the benefits of the approach and demonstrate its possible outcomes in activities such as object dating, survey operations, typology analysis, etc. Ultimately, the visual codification should foster inter-corpus or intra-corpus comparisons with time slots and spatial coverage as variables (for instance, ceilings in a region over three centuries, profiles of different objects at Time $\mathrm{T}$ over regions, etc.).

\section{CONCLUSION}

Although the two experiments we conducted clearly differ in a number of (corpus, documentary sources, historical periods covered, and implementation) they both underline the necessity to work out a methodological framework aimed at clarifying the relations of an architectural concept to its geometrical features. Beyond the actual developments achieved, outcomes should really be read as methodological, in the sense of [15]. Let us summarise some of them:

- Handling mouldings using a generic theoretical model of its components favours reusability and cross-examination of cases.

- Handling mouldings using a generic theoretical model of its components helps underlining the differences between a moulding's « semantic content » and its " geometric container ».

- Accordingly, the semantic content can be exploited in an information and knowledge visualisation perspective, may the geometric container be fully defined or not (a priority when dealing with historic artefacts, often damaged or incomplete)

- It appears possible to subdue the geometric level of a moulding's description to its semantic level.

In other words, results show that developing scientific visualisation practices (in the sense of [18]), on the corpus of mouldings, appears within reach provided an appropriate knowledge modelling effort is carried out prior to the handling of geometrical features.

\section{REFERENCES}


[1] Barberot, E. “Aide mémoire de l'architecte et du constructeur” Ch.Béranger, Paris 1922

[2] Palladio, A. "The four books of architecture". New York : Dover Publications 1965 (orig. 1570)

[3] Wittkower, R. “Architectural principles in the age of humanism”. John Wiley \& Sons 1998.

[4] Harris, Cyril M. "Illustrated Dictionary of Historic Architecture” Dover publications NY 1983

[5] Koch, W, “Style w Architekturze” Bertelsmann publishing Warszawa 1996

[6] Ching, Francis D.K, “A Visual Dictionary of Architecture” Van Nostrand Reinhold 1996

[7] Rattner, D, "Parallel of the classical orders of architecture”. Acanthus Press NY, 1998

[8] Tajchman, J, “Stropy drewniane w polsce. Propozyca systematyki”. Ośrodek dokumentacji zabytków, Warszawa 1989

[9] Ducournau, R., Euzenat J., Masini G., Napoli A., "Langages et modèles à objets. Etat des recherches et perspectives” INRIA 1998

[10] Conway, D, , “Object-oriented Perl” Manning, Greenwich, 2000

[11] Blaise, J.Y, Dudek, I, "Règles d'identification et méthodes de visualisation d'objets architecturaux”,
Proc. EGC 2004 conf. (Knowledge extraction and management), Revue des Nouvelles Technologies de l'Information, vol2, Cépaduès-Edition, ISBN 2.85428.633.2 pp 573-584, 2004.

[12] Blaise, J.Y, Dudek, I, “Terminology analysis inspires relations in a knowledge structure”, Proc. TKE 2008, 8th Int. Conf. on Terminology and Knowledge Engineering, ISBN 87-91242-50-9, pp 89-105, 2008.

[13] Ramondino, F "From point cloud to surface : the modeling and visualisation problem” ISPRS, vol XXXIV- 5/W10- 2001.

[14] Blaise, J.Y, Dudek, I, "From artefact representation to information visualisation: genesis of informative modelling”, Proc. Smart Graphics Int. Conf, Springer, LNCS ISBN 978-3-540-28179-5 pp 230-236, 2005.

[15] Blaise, J.Y, Dudek, I, “Informative modelling”, MIA Journal (online) vol1S, 2007.

[16] Bertin, J; "Sémiologie graphique”, EHESS 1967/1998.

[17] Tufte, E.R.: "Beautiful evidence”, Graphics Press, Cheshire, 2006.

[18] Spence, R, “Information vizualisation” Addison Wesley ACM Press 2001. 